\title{
Converging Lines: Towards the Integration of Second Language Research and Teaching
}

\author{
Bambang Yudi Cahyono
}

\begin{abstract}
Despite the increasing research in second language acquisition, a gap seems to exist between researchers' technical knowledge and teachers' practical knowledge. This is evident from a review of research studies in form-focused instruction summarized in this article. Additional review of articles in the teaching of writing also leads to a similar conclusion. The theoretical development of the writing process does not seem to provide many insights for teachers to apply the process approach to the teaching of writing. The results of the two reviews then indicate that an attempt is required to relate second language research to teaching. Theoretical-pedagogical research, action research, and participatory research are referred to as models of research that can bridge the gap. A review of sample studies recently conducted demonstrates how the integration between technical and practical knowledge can be achieved through the three types of research.
\end{abstract}

Keywords: theoretical knowledge, practical knowledge, form-focused instruction, teaching of writing, process writing, theoretical-pedagogical research, action research, participatory research, second language research, second language teaching.

This article examines the relationship between second language research and teaching. The view of Rod Ellis in his TESOL Quarterly article (Vol. 32, No. 1, Spring 1998) is used as the main reference. Ellis emphasized the importance of integrating the work of researchers with the endeavors of teachers in the classroom. He eventually managed to propose three frameworks for how the development of researchers' technical knowledge can be tightly connected with that of teachers' practical knowledge. Although Ellis based his proposal on the results of the research studies of form-focused instruction, by no means is form-focused instruction the only area in which the relationship between research and teaching can be made. Therefore, this article deals with research studies on second language writing to provide more evidence in the essence of, as Ellis has suggested, integrating research and teaching.

This article initially discusses Ellis' concern about the discrepancy of knowledge that is evident in the work of researchers and teachers. It then briefly presents options in form-focused instruction that Ellis has chosen to highlight for the beginning of integration of research and teaching. Next, Ellis' proposals are delineated and commented on, leading to the necessity for providing another area of support for the proposals. In this case, second language writing is used as that support. Confirming Ellis' proposals, this article ends by emphasizing again the crucial argument over the importance of integrating research and teaching in second language acquisition.

\section{Discrepancy between Research and Teaching}


In his article, Ellis (1998) highlighted the discrepancy in the development of knowledge that exists between the professions of teacher and researcher. Ellis argued that because of classroom demands, teachers require and seek to build practical knowledge of what and how to teach. In contrast, motivated by a system that encourages theoretical understanding of issues, researchers in universities are committed to develop technical knowledge.

In addition to the different settings where the two types of knowledge flourish, both types have different characteristics. Ellis characterized technical knowledge as a form of declarative knowledge that has been codified. This type of knowledge can be analyzed critically and can be confirmed or rejected systematically. As general knowledge containing statements that can be applied to many specified cases, technical knowledge cannot be applied easily to make decisions on a day-to-day basis. Unlike technical knowledge, practical knowledge is not explicitly realized. Working mainly on the intuition basis, this type of knowledge develops through experience and manifests itself only in practice. The procedural nature of practical knowledge makes this knowledge useful for helping teachers cope with particular cases efficiently.

In his article, Ellis is deeply concerned about the applicability of technical knowledge in teaching situations. It is true that teachers attempt to use some technical knowledge in their teaching preparation activities. However, referring to the evaluation work of Pennington and Richards (1997), Ellis believes that integrating technical and practical knowledge is not an easy task for many teachers. Ellis then describes how a mutual relationship can be formulated between technical and practical knowledge. For this purpose, Ellis refers to research studies of form-focused instruction in second language acquisition.

\section{Form-Focused Instruction and the Options}

Research studies in form-focused instruction have moved from focus on forms to be contrasted with focus on meaning into focus on forms imposed on meaningful communicative activities. The issues are, among others, types of form-focused instruction that are more beneficial than others, and the relationship between formfocused instruction with other aspects of learning such as timing and learner difference (Spada, 1997; Doughty \& Williams, 1998). In dealing with types of form-focused instruction, Ellis characterizes differences in instruction according to options based on the computational model of how learners acquire a second language.

According to the computational model of second language acquisition, Ellis argues, learners process input in a mental black box. This mental machine also governs the flow of output. As Ellis (p. 43) shows in his diagram reproduced here in Figure 1, the computational model contains several points for teachers' intervention through formfocused instruction. He describes intervention in Point A as structured input, Point B as explicit instruction, Point $\mathrm{C}$ as production practice, and Point $\mathrm{D}$ as negative feedback. Within these options for intervention, Ellis discussed some of the problems teachers may encounter in applying the results of research studies originally developed for the building of technical knowledge. 


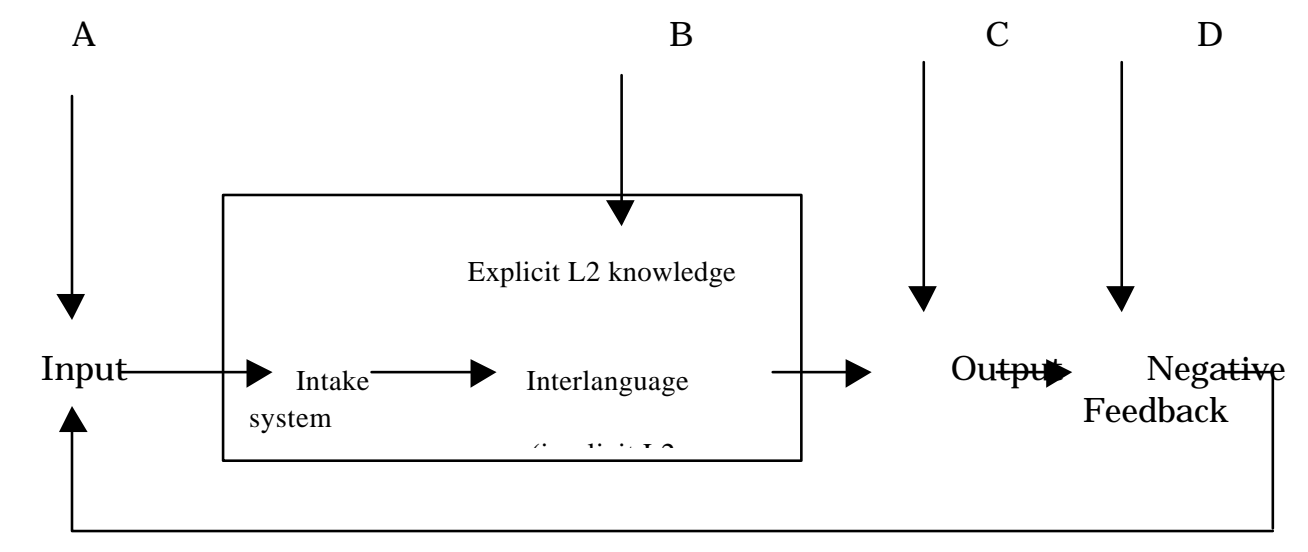

\section{Figure 1. \\ A Computational Model of L2 Acquisition}

Structured-input is based on the principle that acquisition takes place when learners are required to attend to the new structure in input. The procedures in this option involve tasks that ask learners to listen to or read texts and to show their understanding of them. The learners respond to the tasks containing input by providing nonverbal reactions such as ticking a box. As far as Ellis is concerned, a considerable number of research studies have been carried out in this option (e.g. VanPatten \& Oikkenon, 1996). However, the consensus has not been reached because of different study designs, contradictory conclusions, and failure in showing any effect on unplanned language. One thing which is clear about this option is that the practice of structuredinput, as Ellis said, "may provide a useful alternative to production practice" (p. 47).

The explicit instruction option offers either an explicit teaching of rules or a chance for the learners to discover the rules for themselves. Oral and written explanations of grammatical rules with or without follow-up exercises are common procedures to be applied. An activity for this option is the use of consciousness-raising tasks. In these tasks, learners are required to study texts describing how a specified grammatical rule operates. Research has been conducted in the line of this option (e.g. Fotos, 1994). However, according to Ellis, the applicability of the results is questionable because the longer effects of these studies are not known as the studies usually do not include a delayed test. Another limitation persists because communicative behavior tests have been excluded from the studies, putting the reliability of the test used in doubt. Ellis concludes that the results of research in this option cannot be applied directly for pedagogical purposes.

The production practice option emphasizes the important role of production in second language acquisition. Automatic production of the target structure is triggered through exercises varying from tasks involving controlled text-manipulation to those containing freer text-creation. According to Ellis, production practice directed to a particular structure is still questionable. He suspects that such exercises cannot help learners construct the kind of knowledge required for communication. One of the reasons is that learners have their own syllabus that guides their sequence of grammatical development. Although the efficacy of production practice is not yet confirmed, this option has provided a clear contribution to the development of skill and knowledge aspects of second language learning. To apply this option in the classroom 
then, teachers still need to consider the types of practice to provide. Therefore, more research studies are needed to investigate which kind of practice is the most effective.

The last option posits that learners can be helped to notice the gap between grammatically correct production and their incorrect production through negative feedback. It is believed that the practice of giving negative feedback tends to be more successful in the context of activities emphasizing meaning rather than form. Negative feedback may be employed in various ways such as recast, explicit correction, clarification requests, metalinguistic feedback, elicitation, and repetition (Lyster \& Ranta, 1997). Ellis believes that, although a considerable number of research studies on negative feedback have been carried out, the value of negative feedback is still uncertain. This is because of the opposing view that correction does not contribute to language development. Furthermore, it is not yet known which type of feedback is the most effective. An essential value of feedback lies in its contribution to the kind of implicit knowledge used in communication. This option then contains another discrepancy between the technical knowledge and the need for teachers to correct errors with a reasonable basis.

\section{Ellis' Proposals and Comments}

The four options in form-focused instruction illustrate the gap between technical knowledge and practical knowledge. According to Ellis, the remaining problems in the research studies include the rare use of random sampling, the generalizability of the research, and the conflicting nature of the findings. The most serious problem is the false assumption that such studies can be used as a basis to make pedagogical decisions. This kind of assumption does not place researchers and teachers in a position of communicating knowledge that will work better in the classroom, leaving the teachers to use their own practical knowledge. Ellis then suggests that an attempt be made to relate research to teachers' practice.

To relate research and practice, Ellis adopts three models outlined by Weiss (1977) for relating research-based knowledge to professional activity. In the theoreticalpedagogical research, the development of technical knowledge is based on theoretical issues containing pedagogical implications relevant to teachers. Although this first model tends to be researcher-led, it can serve as a source of specific provisions that teachers may apply in the classroom. The second model is action research. In this model, teachers identify potential problems and carry out their own research. In the implementation of this model, the provisional specifications from the theoreticalpedagogical model can be investigated. The last model is participatory research that promotes collaborative work between researchers and teachers. In this interactive model, an opportunity has to be provided for the teachers to control decision-making for the purpose of classroom application.

It is necessary to examine further whether Ellis has a reasonable basis for suggesting the gap. Several years after the work of Weiss, Lightbown (1985) argues that second language research does not inform teachers about issues of 'great expectations', i.e. what and how to teach. However, Lightbown notes that second language acquisition research provides some explanatory support for communicative language teaching. Following Weiss' suggestions and Lightbown's evaluation, research in second language acquisition may have led to the exploration of issues related to practical problems in classrooms. If Ellis highlights the gap between technical and practical knowledge more 
than ten years later, then this should be taken into account with care. Therefore, further evidence is needed to justify Ellis' evaluation.

Ellis considers form-focused instruction as "one of obvious potential relevance to language teaching" (p. 42). His ultimate goal in choosing form-focused instruction as an example is to integrate research and teaching in second language acquisition. To prove whether Ellis is justified in suggesting the gap and in proposing the integration, it is necessary to examine the same issues in another area of second language acquisition. To perform such an examination, the next section reviews the development of knowledge related to the teaching of second language writing. It is expected then that form-focused instruction together with the teaching of second language writing will provide further support for reaching the goal of integrating research to teachers' practice in second language acquisition.

\section{Process Approach in the Teaching of Writing}

The current approach to the teaching of writing focuses on what goes on when learners write and what the teacher can do to help the learners get into the natural writing process. This approach to the teaching of writing is called the process writing approach (White \& Arndt, 1991; Johnston, 1996). According to this approach, writing is considered a way of learning and developing as well as a communication skill. In this perspective, before writing, writers are thought to know only partial ideas of what they are going to write (Caudery, 1995). In fact, many new ideas appear during the act of writing. In addition, the process writing approach views writing as a creative process consisting of a series of stages occurring recursively throughout the process and feeding on one another (Raimes, 1987).

The development of the process writing approach may be attributed to two reasons. First, the process writing approach has appeared as a correction of the previous approach to writing (Johnston, 1996). In the previous product-oriented approach, students were invited to imitate a model text in order to reinforce a certain structure. The old model did not reveal how learners could achieve the product. Second, the process writing approach reflects what skilled writers do when they write. Sommers (1980) suggested that skilled writers tended to use early drafts experimentally and were willing to make substantial changes to them, while unskilled were much more concerned about details from the outset. Furthermore, unskilled writers were determined not to commit errors and therefore attended to them prematurely, while the more skilled writers devised strategies that allowed them to pursue the development of their ideas without being sidetracked (Zamel, 1983; Raimes, 1985; 1987).

Although it has been conclusively proven that the process of writing consists of several stages, researchers classify the stages differently. Flowers and Hayes (1980) argue that the process of writing includes planning, remembering, writing, and rereading. Caudery (1995) states that planning, drafting, and revising take place throughout the process of writing. A more detailed account of stages of writing has been proposed by White and Arndt (1991) who argue that stages in process writing include generating ideas, focusing, structuring, drafting, evaluating, and reviewing, which all interact recursively. The first three stages - generating ideas, focusing, and structuring - are self-explanatory activities classified as the pre-writing stage, while the writing activity starts from drafting. Drafting is concerned with how ideas can be organized and how readers can be led to a conclusion with a sense of completion. Evaluation deals with 
the cultivation of a sense of responsibility for being critical to the writing. Re-viewing aims at developing critical capacities and enriching the repertoire of linguistic resources for writing. White and Arndt's model of writing is shown in Figure 2.

Figure 2.

\section{White and Arndt's Model of Writing}

\section{Connecting to Ellis' Arguments}

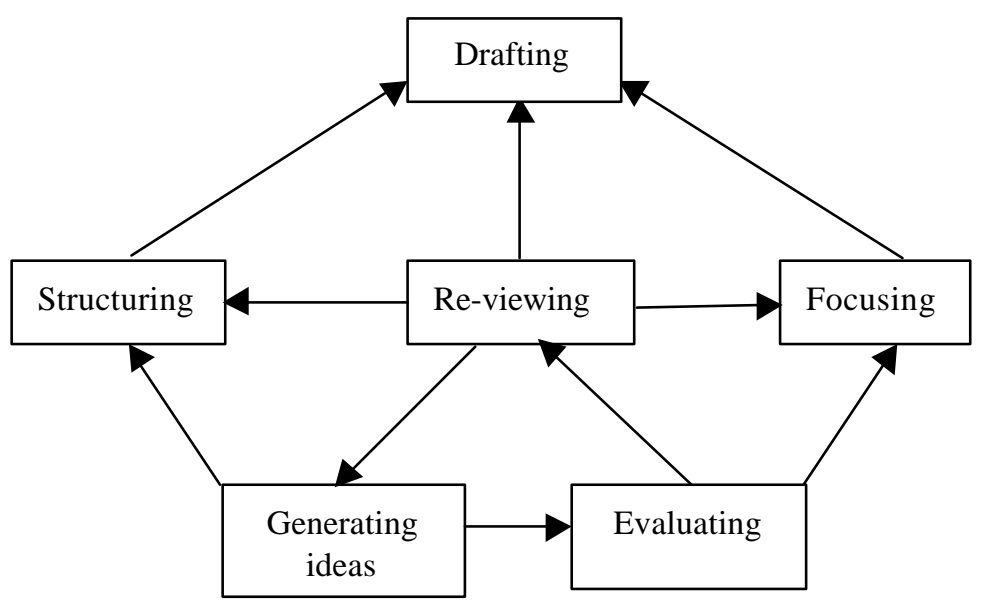

It is interesting then to connect some aspects of the teaching of second language writing with form-focused instruction as stipulated by Ellis who notes that research in form-focused instruction has turned to an issue that is closely related to the teacher's perspective. The issue is what kind of form-focused instruction works best to draw the learner's attention to a linguistic feature as necessitated by a communicative demand (Doughty \& William, 1998). Similarly, the process writing approach aims to provide learners with skills they can use to "work out their own solutions to the problems they set themselves" (White and Arndt, 1991, p. 5). To reach the purposes of either formfocused instruction or process writing, an intervention from the teacher is considered important.

A crucial point is that the proposal should be based on a guiding principle that justifies what will work best for the application in the classroom. Ellis (1998) based his description of the teaching of grammar on a computational model of second language acquisition. Analogous to Ellis, Hairston (1982) suggested that teachers intervene in learners' writing during stages in the process of writing. In this case, although other models of the writing process have been proposed (Flowers \& Hayes, 1980; Caudery, 1995), White and Arndt's model of writing fulfills the criteria of a good model as specified by Rivers (1987). A good model summarizes the past, represents the present, and predicts the future and reflects the issue being modeled with justifiable considerations. White and Arndt show that writing is a recursive process within which a number of stages feed into one another.

The discrepancy between technical knowledge and practical knowledge was evident in the teaching of writing. Hairston's (1982) recommendation for teachers to intervene in the learners' writing process was followed by a significant number of theoreticalpedagogical research studies in the following years (Raimes, 1985; 1987). However, an 
evaluation by Zamel (1987) which was carried out five years later indicated that research into the writing process was not informing pedagogy. What Zamel argued was thus similar to Ellis' concern about the discrepancy between technical knowledge and practical knowledge.

It is necessary then to examine the research on teachers' intervention in the form of feedback. The assumption underlying the importance of feedback is that feedback in the teaching of writing is parallel to revision of drafts in the process of writing (Dheram, 1995). In addition to feedback, teachers' experience and knowledge need to be examined in order to know whether teachers are aware of developments in the theoretical bases for the teaching of writing and whether they base their teaching on this basis.

\section{Studies on Feedback for Learners' Writing}

Studies investigating effects of feedback are commonly oriented to overall feedback for the learners' writing. Dheram (1995) investigated how learners responded to feedback on both language use and content. Five respondents were selected from a tenweek pre-sessional course conducted at a British university. First drafts were discussed in class and in peer feedback sessions. The second and final drafts were then produced. The respondents' first and second drafts were collected and the changes they made while revising the drafts were examined. The investigation resulted in a rough list of the various changes each respondent made during revision. Examination of form-focused changes indicated that form revisions were mostly sentence-level and they did not affect meaning. Examination of text-focused changes indicated that learners tried to make meaning clearer, to emphasize tone and style, and to add arguments with fresh details different from the ones used in the earlier draft. It was evident from the revised versions then that learners used feedback as reference for addition, deletion, and rearrangement of their ideas.

Research studies have examined feedback not only from the teachers but also feedback from peers. Villamil and Guerrero (1998) carried out a study involving fourteen ESL college students to investigate the impact of peer revision on writers' final drafts. Peer sessions were characterized by collaborative work between readers and writers in the revision task. In order to work well in the task, students were trained to practice evaluating sample student essays using the writing prompts. They then discussed their revisions with the class. The data for analysis consisted of transcripts of fourteen audio recordings, first drafts, final versions, and comments written on the revision sheets. The results showed that peer assistance had a substantial effect on revising because some points of revision during the interaction were incorporated into final versions. However, some other points of revisions were not incorporated and self-revisions were added. This indicated that it was the writers' prerogative to choose from the suggestions and to exercise authorial control.

Boughey (1997) examined the effect of feedback in a class in which students worked in groups to finish a writing task. Multiple drafts that the students produced for the joint assignment were then submitted to the lecturer for feedback. Evaluation at the first draft stage was based on a descriptive marking scale addressing issues of content and rhetorical development. Analysis of drafts after feedback indicated that students tried to make links between propositions. The number of unsupported assumptions in the first draft indicated that these students had not internalized the rule fundamental to academic discourse that claims must be substantiated. The examination of consecutive 
drafts of writing also showed that feedback was crucial in getting students to be more explicit and in making learners express propositions in their writing more rigorously.

The three studies of the effect of feedback on learners' writing clearly reflect the importance of the process writing approach in the classroom. However, do they bridge the gap that Ellis (1998) highlighted between researchers' technical knowledge and teachers' practical knowledge? The studies by Dheram (1995), Villamil and Guerrero (1998), and Boughey (1997) were carried out in the university or college levels and the four researchers are university or college lectures. Referring to Ellis' conviction that researchers are those who, more often than not, work in universities, these studies cannot be used as an indication that technical knowledge has been transformed into the teachers' enterprise. It is necessary then to examine teachers' knowledge of theoretical development in the teaching of writing and their practical experience.

\section{Teachers' Knowledge and Experience}

An examination of teachers' knowledge and experience will reveal whether a gap exists between their technical and practical knowledge. A relevant study for the purpose is one by Pennington, et al. (1997) which examined the ways teachers teach English-asa-second-language (ESL) writing in the Asia-Pacific region. This study also examined teachers' awareness about the theoretical issues of writing which had developed from product-oriented to process-oriented paradigms.

In their study, Pennington, et al. (1997) described the teachers' views and practices in the Asia-Pacific region on the teaching of writing. Two issues raised were whether teachers in the region had the same or different teaching circumstances and views on the teaching of writing, and whether teachers' orientation could be described as process, product, or a combination of both approaches. A questionnaire was distributed to highlight the contrast between the process and product approaches to the teaching of writing. The questionnaire solicited teachers' general view on the teaching of writing, important features of their method, and their specific classroom practices based on ideal and actual conditions.

The research data were gathered from five countries, i.e. Australia, New Zealand, Hong Kong, Japan, and Singapore. The study involved 29 native teachers, 17 non-native teachers of English, different types of courses, and different students taught by the surveyed teachers.

The study resulted in several findings. First, the native teachers of English among the participating teachers in all countries were more process-oriented in their responses than the non-native teachers of English. Second, the teachers from Australia and New Zealand, who had smaller classes, tended to be more process-oriented than teachers in Asia. Third, some of the teachers in each country felt that they needed to teach at both ends of the process and product scales and some others preferred a combination of process and product elements.

A common view expressed by the teachers was that they must compromise their teaching ideals to handle the reality of their job situation. The difference between the ideal and actual practice was attributed to teachers' knowledge and perceptions about writing practice. Many teachers in all countries admitted that their knowledge of writing practice was limited, particularly regarding the process approach. Comments by some respondents suggested that process writing was in fact not a realistic alternative and it tended to be conceptualized as attractive, but abstract and impractical. In 
general, the survey results gave evidence that a gap does exist between teachers' ideal and actual practice in the teaching of writing.

It is interesting then to relate the research findings in the context of second language writing and Ellis' conviction of the discrepancy between technical and practical knowledge as he examined the options in form-focused instruction. As discussed earlier, research on the effects of feedback cannot justify the transformation of technical knowledge in the process of writing to the teaching of writing. Furthermore, Pennington, et al's (1997) study indicated that there was a gap between teachers' practices and the theoretical basis for those practices. The findings of research on the two aspects of the teaching of writing then provide further evidence for Ellis' (1998) conclusion that there is a gap between researchers' technical and teachers' practical knowledge. Restating what Ellis has suggested, an attempt should be made to relate these two types of knowledge.

\section{Integrating Second Language Research and Teaching}

Ellis has emphasized that three types of research - theoretical-pedagogical research, action research and participatory research - are most likely to lead to the integration of theoretical and practical issues. The three types of research are oriented to provide answers for questions concerning issues related or potentially related to classroom practice. This section deals with how such kinds of research are carried out by presenting sample research studies. In addition, contributions of the sample research studies to answer practical problems raised in the studies are also discussed.

Theoretical-pedagogical research aims at developing technical knowledge based on theoretical issues relevant to teachers' professional practice. In this kind of research, an attempt is made to investigate issues concerning what is universally true, or at least generalizable to other contexts. This type of research can be a source of insights that can be tested in the classroom. An example of this type is research by Paribakht and Wesche (1997).

Motivated by results of previous research that incidental learning is a major avenue to vocabulary development (e.g. Krashen, 1989), Paribakht and Wesche hypothesized that reading could be made more useful by complementing it with vocabulary enhancement activities. The subjects of this study were 38 young adults from a variety of L1 backgrounds in the fourth semester of university. The classroom experiments used instructional procedures designed to increase the salient and cognitive processing of targeted words encountered by L2 students in reading texts. The group was given vocabulary exercises grouped into five hierarchical categories of mental processing activity. The Vocabulary Knowledge Scale was used to track the acquisition of the target words. It was found that, although reading for meaning is likely to produce significant results in vocabulary acquisition, when such reading is supplemented with specific vocabulary exercises, greater gains result for the targeted words.

The objective of action research is to provide answers to questions that teachers identify in their profession in order to apply what they have discovered to their practical action. Although the questions may also be the ones provided by theoretical-pedagogical research, the teachers take responsibility to carry out the investigations. This type of research is thus focused on individual or small-group professional practice and is not so concerned with making general statements (Wallace, 1998). Widiati and Widayati's (1997) study can be an example of an action research. 
In their EFL writing classrooms, Widiati and Widayati (1997) expected their students to get as much language exposure as possible since they did not use English outside the classroom. They carried out a study investigating how a conference between teacher and students provided students with immediate, meaningful responses to their writing. The study found out that not only did the conference involve the students in the communicative process of making meaning, but it also geared the students to focus their talking. Widiati and Widayati considered that the research was a preliminary study, so they also suggested the possibility of conducting another cycle in the action research which would investigate the effect of increased oral skills on their students' writing, or vice versa.

Participatory research combines some elements in the first two types of research. This type of research is oriented to practical problems identified and studied collaboratively by a researcher and a teacher. The collaborative work will then provide the teacher with valuable insights in the process of decision making for the classroom. An example of this type is a research study by Doughty and Varela (1998).

Doughty and Varela (1998) studied a practical issue that Varela, the teacher, encountered in her science classroom. Varela's students were required to use past time references when they made reports of science experiments. Doughty and Varela examined whether and how learners' attention can be drawn to simple past and conditional features by corrective recasts without distracting them from their original communicative intent. Thirty-four school students studying science at an intermediate ESL level were involved. It was found that corrective recasts were effective in solving the practical problem of how to make students learn to use past references.

The three research studies by Paribakht and Wesche (1997), Widiati and Widayati (1997), and Doughty and Varela (1998) which were carried out within the models that Ellis emphasized show how the relation of research and teaching works. They can bring results not only for the development of second language research, but also for the solution to practical problems in the classroom.

\section{Conclusion}

This article has discussed Ellis' concern about the discrepancy between researchers' technical knowledge and teachers' practical knowledge. This gap is evident from the discussion of form-focused instruction under the computational model of second language acquisition. Such a gap in fact also exists in the area of the teaching of writing following the process writing approach. Both areas of study then provide a reasonable background for justifying Ellis' suggestion that the two types of knowledge could be integrated through three research models. Converging with Ellis' proposal, recent research studies seem to reflect a growing trend to combine language research and teaching. These two converging lines of thought and action then may be an indication of a good prospect for an intense relation between technical and practical knowledge in second language acquisition.

\section{Acknowledgements}

I am deeply grateful to Dr. Patsy M. Lightbown of Concordia University, Montreal, Canada, who gave me encouragement and ideas in writing the article. I am also 
thankful to Dr. Verzosa in Manila, the Philippines, whose notes and comments were invaluable to me in making the final revisions.

\section{References}

Boughey, C. (1997). Learning to write by writing to learn: A group-work approach. ELT Journal, 51, 126-134.

Caudery, T. (1995). The process approach. Paper presented at the British Council summer school on writing in the classroom, University of Surrey, England.

Dheram, P.K. (1995). Feedback as a two-bullock cart: A case study of teaching writing. ELT Journal, 49, 160-168.

Doughty, C. \& Williams, J. (1998). Focus on form in classroom second language acquisition. Cambridge: Cambridge University Press.

Doughty, C. \& Varela, E. (1998). Communicative focus on form. In C. Doughty \& J. Williams (Eds.), Focus on form in classroom second language acquisition. Cambridge: Cambridge University Press, 114-138.

Ellis, R. 1998). Teaching and research: Options in grammar teaching. TESOL Quarterly, 32, (39-60.

Flower, L. \& Hayes, J. R. (1980). The cognition of discovery: Defining rhetorical problem. College Composition and Communication, 31, 76-88.

Fotos, S. (1994). Integrating grammar instruction and communicative language use through grammar consciousness-raising task. TESOL Quarterly, 28, 323-351.

Hairston, M. (1982). The winds of change: Thomas Kuhn and the revolution in the teaching of writing. College Composition and Communication, 31, 76-88.

Johnston, H. (1996). Survey review: Process writing in coursebooks. ELT Journal, 50, 347-355.

Krashen, S.D. (1989). We acquire vocabulary and spelling by reading: Additional evidence for the input hypothesis. Modern Language Journal, 73, 440-464.

Lightbown, P. M. (1985). Great expectation: Second language acquisition research and classroom teaching. Applied Linguistics, 6, 173-189.

Lyster, R. \& Ranta, L. (1997). Corrective feedback and learner uptake: Negotiation of form in communicative classrooms. Studies in Second Language Acquisition, 19, 37-66.

Paribakht, T.S. \& Wesche, M. (1997). Vocabulary enhancement activities and reading for meaning in second language acquisition. In J. Coady, \& T. Huckin (Eds.), Second language vocabulary acquisition. Cambridge: Cambridge University Press, 174-202.

Pennington, M. \& Richards, J. (1997). Reorienting the teaching universe: The experience of five first-year teachers of English in Hong Kong. Language Teaching Research, 1, 149-178. 
Pennington, M. Costa, V. So, S. Shing, J. L.W. Hirose, K. \& Niedzielski, K. (1997). The teaching of English-as-a-second-language writing in the Asia-Pacific region: A cross-country comparison. RELC Journal, 28, 120-143.

Raimes, A. (1985). What unskilled ESL students do as they write: A classroom study of composing. TESOL Quarterly, 19, 229-257.

Raimes, A. (1987). Language proficiency, writing ability, and composing strategies: A study of ESL college student writers. Language Learning, 37, 439-468.

Rivers, W. M. (1987). Interactive language teaching. Cambridge: Cambridge University Press.

Sommers, N. (1980). Revision strategies of student writers and experienced adult writers. College Composition and Communication, 31, 378-388.

Spada, N. (1997). State of the art: A review of classroom and laboratory research. Language Teaching, 30, 73-87.

VanPatten, B. \& Oikkenon, S. (1996). Explanation versus structured input in processing instruction. Studies in Second Language Acquisition, 18, 495-510.

Villamil, O. S., \& Guerrero, M. C. M. de. (1998). Assessing the impact of peer revision on L2 writing. Applied Linguistics, 19, 491-514.

Weiss, C. (1977). Using social research in public in policy making. Lexington: DC Heath.

White, R. \& Arndt, V. (1991). Process writing. London: Longman.

Widiati, U. \& Widayati, S. (1997). Out of a writing conference: Speaking-writing connection. TEFLIN Journal, 8, 68-78.

Zamel, V. (1983). The composing processes of advanced ESL students: Six case studies. TESOL Quarterly, 17, 165-187.

Zamel, V. (1987). Recent research on writing pedagogy. TESOL Quarterly, 21, 697-715. 